ИЗВЕСТИЯ АКАДЕМИИ НАУК ЭСТОНСКОИ ССР. ТОМ 28 ХИМИЯ. 1979, № 4

\title{
СИНТЕЗ ПОЛИАМИДОВ ИЗ ДИМЕТИЛОВЫХ ЭФИРОВ ДИКАРБОНОВЫХ К КИСЛОТ
}

В настоящее время наиболее распространенным методом получения найлона 66 и найлона 610 является поликонденсация адипиновой и себациновой кислот гексаметилендиамином (ГМДА) с предварительным получением солей названных кислот.

Технологически выгодно получать полиамиды (ПА) прямо из диметиловых эфиров дикарбоновых кислот (ДЭК) и ГМДА, исключая стадии гидролиза диэфиров и получения солей с ГМДА. Сырьевая база для подобного производства в СССР уже имеется или может быть легко создана при организащии переработки отходов имеющихся производств. При выработке капролактама ежегодно остается мното неиспользованных отходов в виде смеси дикарбоновых кислот $\mathrm{C}_{4}-\mathrm{C}_{6}$, разделение которых легко осуществимо после перевода кислот в соответствующие диметиловые эфиры.

В настоящее время наиболее широко применяется метод получения высших дикарбоновых кислот, заключающийся в окислении углеводородов $\mathrm{HNO}_{3}$, в результате чего неизбежно получается и смесь низших дикарбоновых кислот, которые можно разделить в виде их диметиловых эфиров [']. Вышеприведенное указывает на целесообразность синтеза ПА из ДЭК.

Известны способы получения ПА из диметиловых эфиров и ГМДА $\left[{ }^{2,3}\right]$. Для поддержания постоянного молярного соотношения мономеров предлагается проводить поликонденсацию в присутствии воды [4], но это затрудняет соблюдение температурного режима и тем самым снижает скорость реакции. Все названные методы синтеза ПА до сих пор не нашли практического применения.

Нами разработан способ синтеза высокомолекулярных ПА из ДЭК и ГМДА под действием катализаторов типа $\mathrm{Ti}(\mathrm{OR})_{4}$, где $\mathrm{R}$ - этил, пропил, бутил, изобутил [5]. Названный способ позволяет проводить поликонденсацию в одну стадию, т. е. исключает предварительный гидролиз диэфиров, выделение кислот и получение солей последних с диамином. $\mathrm{Ti}(\mathrm{OR})_{4}$ особенно значительно ускоряет первую стадию поликонденсации (процесс образования низкомолекулярных олигомеров), и при этом не наблюдается получения нерасплавимого преполимера, что иногда случается при проведении реакции в расплаве без катализатора и воды (см. таблищу).

О степени поликонденсации можно судить по изменению содержания метоксильных групп в ПА. Поскольку до сих пор нет общепринятой методики определения концевых метоксильных групп в ПА, то нами разработано газохроматографическое определение их в ПА, которое применимо и для анализа полиэфиров [ $\left.{ }^{6}\right]$. 


\begin{tabular}{|c|c|c|c|c|c|c|c|}
\hline \multirow{2}{*}{$\begin{array}{c}\text { Способ поликон- } \\
\text { денсации }\end{array}$} & \multicolumn{6}{|c|}{$\begin{array}{c}\text { Степень превращения диэфиров (\%) } \\
\text { при } 200{ }^{\circ} \mathrm{C} \text { после: }\end{array}$} & \multirow{2}{*}{$\begin{array}{l}\text { Удельная вяз- } \\
\text { кость полимера } \\
(\eta) \\
\text { * }\end{array}$} \\
\hline & 5 мин & 15 & мин & 30 мин & $60 \mathrm{мин}$ & 180 мин & \\
\hline $\begin{array}{l}\text { В присутствии } 0,1 \% \text { ка- } \\
\text { тализатора }\end{array}$ & 66,3 & & 82,0 & 83,5 & 89,1 & 91,9 & \multirow{3}{*}{$\begin{array}{l}\text { после } 9-12 \text { ч } \\
0,8-1,1 \\
\text { после } 12-13 \text { u } \\
0,6-1,0 \\
\text { после } 12-13 \text { ч } \\
0,5-0,9\end{array}$} \\
\hline $\begin{array}{l}\text { В присутствии } 2 \text { молей } \\
\text { воды }\end{array}$ & 39,4 & & 54,4 & 68,7 & 78,5 & 83,5 & \\
\hline Без катализатора и воды & 27,1 & & 53,2 & 60,6 & 70,1 & 81,0 & \\
\hline
\end{tabular}

Синтез высокомолекулярных ПА. В колбу, снабженную обратным холодильником и мешалкой, загружаются ГМДА и ДЭК в мольном соотношении $1,03: 1$ и Тi(OR) ${ }_{4}$ в количестве $0,1-0,5 \%$ от веса мономеров. Смесь мономеров в течение $1-2$ ч нагревают от $200^{\circ}$ до $270^{\circ} \mathrm{C}$, затем для облегчения удаления из реакции побочных продуктов закрывают воду в холодильнике и при этой же температуре и непрерывном перемешивании продолжают поликонденсацию в течение 6 ч. Удельная вязкость 0,5\%-ного раствора ПА в трикрезоле 0,7. Для увеличения молекулярной массы ПА подвергают дополнительной поликонденсации при $270^{\circ}$ и остаточном давлении 5 мм pт. ст. в течение $2-4$ ч. После этого удельная вязкость ПА поднимается до 0,8-1,1.

Кинетические данные поликонденсации с $\mathrm{Ti}(\mathrm{OR})_{4}$ рассчитывались только в течение 30 мин от начала реакции при температуре $200^{\circ}$, поскольку в дальнейшем при проведении процесса в расплаве происходит самопроизвольное ускорение реакции путем ориентации мономеров олигомерными цепями [ $\left.{ }^{7}\right]$.

По полученным экспериментальным данным, предполагается следующий механизм реакщии. Соединения типа $\mathrm{Ti}(\mathrm{OR})_{4}$ образуют неустойчивые комплексы с ДЭК $\left.{ }^{[}\right]$:

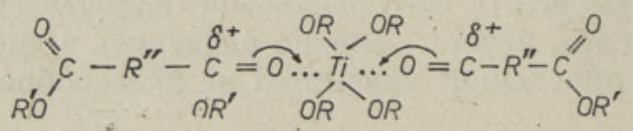

Возникший у атома $\mathrm{C}$ заряд $\delta^{+}$облегчает нуклеофильную атаку этого атома аминогруппой. Элементарный акт катализа поликонденсации можно представить так:

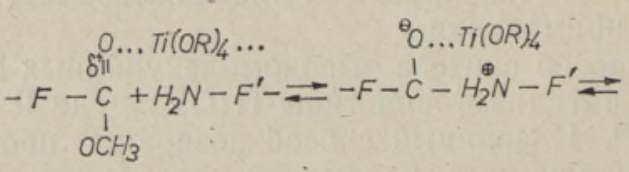

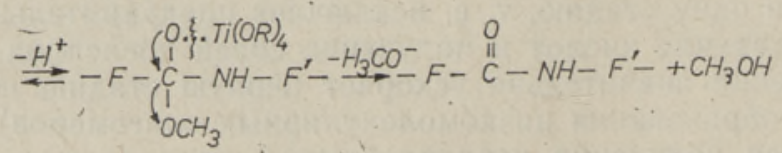

В уравнении реакции символами $F$ и $F^{\prime}$ обозначены фрагменты цепи мономера или полимера, обусловливающие реакционную способность функциональных групп - $\mathrm{COOCH}_{3}$ и $-\mathrm{NH}_{2}$.

Обозначив $\mathrm{CH}_{3} \mathrm{OH}$ как $\mathrm{X},-\mathrm{COOCH}_{3}$ как $\mathrm{Y}, \mathrm{NH}_{2}$ как $\mathrm{Z}, \mathrm{Ti}(\mathrm{OR})_{4}$ как $\mathrm{K}$ и не учитывая обратных реакций, кроме образования комплекса катализатора с ДЭК, можно записать: 


$$
\begin{aligned}
& \mathrm{Y}+\mathrm{K} \underset{k_{2}}{\stackrel{k_{1}}{\rightleftarrows}} \mathrm{YK} \\
& \mathrm{Z}+\mathrm{YK} \stackrel{k_{3}}{\longrightarrow} \mathrm{YZK}_{1} \\
& \mathrm{YZK}_{1} \stackrel{k_{4}}{\longrightarrow} \mathrm{YZK}_{2}^{-}+\mathrm{H}^{+} \\
& \mathrm{YZK}_{2}^{-} \stackrel{k_{5}}{\longrightarrow} \mathrm{K}+\mathrm{CH}_{3} \mathrm{O}^{-}+\mathrm{YZ} \\
& \mathrm{CH}_{3} \mathrm{O}^{-}+\mathrm{H}^{+} \stackrel{k_{6}}{\longrightarrow} \mathrm{X} \\
& \frac{\delta\left[\mathrm{YZK}_{2}^{-}\right]}{\delta t}=-k_{5}\left[\mathrm{YZK}_{2}^{-}\right]+k_{4}\left[\mathrm{YZK}_{1}\right] \\
& \frac{\delta\left[\mathrm{YZK}_{1}\right]}{\delta t}=k_{3}[\mathrm{Z}][\mathrm{YK}]-k_{4}\left[\mathrm{YZK}_{1}\right] \\
& \frac{\delta[\mathrm{YK}]}{\delta t}=k_{1}[\mathrm{Y}][\mathrm{K}]-k_{2}[\mathrm{YK}]-k_{3}[\mathrm{Z}][\mathrm{YK}] \\
& \frac{\delta[\mathrm{K}]}{\delta t}=-k_{1}[\mathrm{Y}][\mathrm{K}]+k_{2}[\mathrm{YK}]+k_{5}\left[\mathrm{YZK}_{2}^{-}\right] \\
& \frac{\delta[\mathrm{Y}]}{\delta t}=-k_{1}[\mathrm{Y}][\mathrm{K}]+k_{2}[\mathrm{YK}] \\
& \frac{\delta[\mathrm{Z}]}{\delta t}=-k_{3}[\mathrm{Z}][\mathrm{YK}] \\
& \frac{\delta\left[\mathrm{H}^{+}\right]}{\delta t}=k_{4}[\mathrm{YZK}]-k_{6}\left[\mathrm{CH}_{3} \mathrm{O}^{-}\right]\left[\mathrm{H}^{+}\right]
\end{aligned}
$$

После преобразования вышеприведенных уравнений, учитывая также то, что в реакционной среде $[\mathrm{Y}]=[\mathrm{Z}]$ и концентрация катализатора не изменяется (т. е. $\delta[\mathrm{K}] / \delta t=0)$, получаем зависимость расхода метоксильных групп от скорости возникновения и разложения комплекса $\mathrm{Ti}(\mathrm{OR})_{4}$ c диэфиром:

$$
\frac{\delta[\mathrm{Y}]}{\delta t}=-\frac{k_{1}[\mathrm{Y}]^{2}}{1-k_{2}[\mathrm{Y}]},
$$

где [Y] - концентрация метоксильных групп, моль/,$t-$ время, мин.

По экспериментальным данным определены максимально соответствующие результатам опытов числовые значения кинетических констант $k_{1}$ и $k_{2}$. Поиск наиболее подходящих значений констант проводился минимизацией суммы квадратных отклонений расчетных данных от экспериментальных [9]. Вычисления осуществлялись с помощью ЭВМ. Числовые значения констант с установленными с 95\%-ной вероятностью пределами достоверности: $k_{1}=0,0783 \pm 0,0035$ и $k_{2}=0,527 \pm 0,039$.

\section{ЛИТЕРАТУРА}

1. Кул а ков В. Н. и др. Мономеры для синтетических волокон. Ч. 1. Тула, 1971.

2. Пат. ФРГ № 899553, 1953. - РЖХ, 1955, 17601 П.

3. Яп. пат. № 1842, 1960. - РЖХ, 1962, 14 П.

4. С м олян 3. С., М а т в е е в а Т. Н. Авт. свид. СССР № 138367. - Бюл. изобретений, 1961, № 10. 
5. Конгас А. А., Киррет О. Г., Когерман А. Р., Мянник А. Н. Авт. свид. СССР № 487093. - Бюл. изобретений, 1975, № 37.

6. Киррет О. Г., Когерман А. Р., Яагус М., Конгас А. А. Микроэлементарный состав некоторых синтетических полимеров и волокон, - Изв. АН ЭССР. Хим. Геол., 1974 , т. 23 , № 1, с. $137-140$.

7. Ж убанов Б. А. Успехи в области равновесной поликонденсации. - Высокомол. соед., 1978 , т. 20 , № 4 , с. $720-741$.

8. Нуделман 3. Н., Новиков А. С. Реакция структурирования полидиметилсилоксанов при холодной вулканизации полисилоксановых каучуков. - Каучук и резина, 1960 , № 5 , с. $17-21$.

9. Т я х т Р. Э., Р а ял о Г. Ю. Пакет программ для определения констант уравнений химической кинетики. Таллин, 1978.

Институт химии

Академии наук Эстонской ССР
Поступила в редакцию

23/I 1979

A. KONGAS, O. KIRRET, G. RAJALO

\section{POLUAMIIDIDE SUNTEES DIKARBOKSUULHAPETE DIMETUOLESTRITEST}

On näidatud, et $\mathrm{Ti}(\mathrm{OR})_{4}$ tüüpi ühendid katalüüsivad dikarboksüülhapete dimetüülestrite polükondensatsiooni heksametüleendiamiiniga, esitatud katalüüsi mehhanism ja mōnede kineetiliste konstantide väärtused.

A. KONGAS, O. KIRRET, G. RAJALO

\section{POLYAMIDE SYNTHESIS FROM DICARBOXYLIC ACID DIMETHYL ESTERS}

$\mathrm{Ti}(\mathrm{OR})_{4}$-type catalysts were found to accelerate the polycondensation of dicarboxylic acid diesters with hexamethylenediamine. Reaction mechanism is suggested, and some kinetic constants are computed. 